\title{
Optimising social procurement policy outcomes through cross-sector collaboration in the Australian construction industry
}

\author{
Martin Loosemore, George Denny-Smith, Jo Barraket, Robyn Keast, Daniel \\ Chamberlain, Kristy Muir, Abigail Powell, Dave Higgon and Jo Osbourne
}

\begin{abstract}
Purpose - Social procurement policies are an emerging policy instrument being used by governments around the world to leverage infrastructure and construction spending to address intractable social problems in the communities they represent. The relational nature of social procurement policies requires construction firms to develop new collaborative partnerships with organisations from the government, not-for-profit and community sectors. The aim of this paper is to address the paucity of research into the risks and opportunities of entering into these new cross-sector partnerships from the perspectives of the stakeholders involved and how this affects collaborative potential and social value outcomes for intended beneficiaries.

Design/methodology/approach - This case study research is based on a unique collaborative intermediary called Connectivity Centre created by an international contractor to coordinate its social procurement strategies. The findings draw on a thematic analysis of qualitative data from focus groups with 35 stakeholders from the construction, government, not-for-profit, social enterprise, education and employment sectors.

Findings - Findings indicate that potentially enormous opportunities which social procurement offers are being undermined by stakeholder nervousness about policy design, stability and implementation, poor risk management, information asymmetries, perverse incentives, candidate supply constraints, scepticism, traditional recruitment practices and industry capacity constraints. While these risks can be mitigated through collaborative initiatives like Connectivity Centres, this depends on new "relational" skills, knowledge and competencies which do not currently exist in construction. In conclusion, when social procurement policy requirements are excessive and imposed top-down, with little understanding of the construction industry's compliance capacity, intended social outcomes of these policies are unlikely to be achieved.

Originality/value - This research draws on theories of cross-sector collaboration developed in the realm of public sector management to address the lack of research into how the new cross-sector partnerships encouraged by emerging social procurement policies work in the construction industry. Contributing to the emerging literature on cross-sector collaboration, the findings expose the many challenges of working in cross-sector partnerships in highly transitionary project-based environments like construction.
\end{abstract}

Keywords: Construction industry, collaboration, intermediaries, risk management, social procurement, corporate social responsibility

\section{Introduction}

The subject of social procurement is a relatively new branch of corporate social responsibility research in construction (Murray and Dainty, 2013; Raiden et al., 2018). In contrast to normal construction procurement which focusses on the delivery of buildings and infrastructure to time, cost and quality objectives (Greenhalgh and Squires, 2011), social procurement involves the deliberate creation of social value through procurement (Barraket et al., 2016). In the context of construction, this involves firms (consultants and contractors) being required by clients to create social value in the communities in which they build as a condition of contract on public sector and private sector infrastructure and building projects (Loosemore, 2016). While social value can be 
created in many ways, most social procurement policies require companies tendering for construction contracts to create new training and employment opportunities for disadvantaged people in project communities who are normally excluded from the labour market (Raiden et al., 2018).

Not all social procurement policies and guidelines are mandatory and prescriptive about the groups targeted (see, for example, the UK's Social Value Public Services Act (2012) and EU public procurement directives [European Union, 2014; ISO 20400, 2017]). However, other social policies are mandatory and prescriptive, targeting disadvantaged groups such as refugees and migrants, Indigenous people, people with disability, ex-offenders, youth at risk, women, Black Americans, Hispanic Americans, Native Americans, other minorities and people who are long-term unemployed (see, for example, US Public Law 95-507 The Public Law 95-507 Act, 1978; the Canadian Procurement Strategy for Aboriginal Business, 2016; South Africa's Preferential Procurement Regulations 2017; Australia's Indigenous Procurement Policy, 2015 and the Victorian Social Procurement Framework 2018).

While new to construction, social procurement has a long history going back to the cooperative movements of the industrial revolution and the US civil rights movements (McCrudden, 2004). However, the contemporary re-emergence of what Barraket (2019) describes as "new social procurement" in countries such as the United Kingdom, Australia, Canada, South Africa and Europe reflects wider trends in "New Public Governance" which emphasise both a plural and pluralist state characterised by collaboration between government, private-sector, third-sector and community organisations in the delivery of social policy to communities (Barraket et al., 2016; Tanekenov et al., 2018). As Bromley and Meyer (2017, p. 947) note, "the burgeoning literature on new public governance emphasises a core shift in government towards a 'plural state' characterised by a blurring of traditional boundaries between non-profit, business and government sectors where multiple interdependent actors contribute to the delivery of public services ...".

Despite some criticisms relating to the distortion of markets and the outsourcing of welfare to the community for economic rather than social reasons (Esteves and Barclay, 2011; Doherty et al., 2014; Cutcher et al., 2019), social procurement policies continue to proliferate in many countries, with the engineering and construction industry being a major focus because of its large size and its significant multiplier-effect into the wider economy (Loosemore, 2016; Tanekenov et al., 2018). However, as Raiden et al. (2018) note, social procurement research has almost exclusively occurred outside construction, and there are few sector-specific insights into the challenges it poses in such industries. Furthermore, the limited research in this area has mainly been undertaken from a single stakeholder perspective and ignored the challenges of cross-sector collaboration which lie at the heart of effective social procurement policy implementation.

While complying with these policies raises many new questions for researchers and practitioners in the engineering and construction industry (Troje and Gluch, 2019), the aim of this paper is to explore the risks and opportunities of cross-sector collaboration from the perspectives of engineering and construction companies, government organisations, third -sector organisations (not-for-profits, charities, social enterprises) and community organisations, which need to collaborate in meeting these new social procurement requirements.

More specifically, this paper seeks to answer two main research questions:

RQ1. What risks and opportunities does social procurement create for key stakeholders involved in implementing social procurement in construction?

RQ2. How do these risks and opportunities affect collaborative potential in these new organisational arrangements? 
These are important gaps in knowledge to address within and outside the field of construction because, as Loosemore et al. (2020) recently reported, cross-sector collaboration is particularly challenging in transitionary, project-based industries like construction. This is because project teams form, disband and reform and move continuously from one community to the next, forming new cross-sector relationships and partnerships to meet changing local community needs and priorities in each project location. Furthermore, as Raiden et al. (2018) and Barraket and Loosemore (2018) note, construction organisations typically see the community as a risk rather than an asset, have little experience of working with third-sector organisations and have strongly established supply chain relationships with industry incumbents which they are reluctant to break.

\section{Cross-sector collaboration in the context of social procurement}

Collaborating across sectors to comply with social procurement requirements to provide training and employment opportunities for disadvantaged groups is complex. For example, in Australia, where this research was conducted, organisations in the construction supply chain subject to these policies have to interact with a complex, decentralised and largely privatised network of approximately 5,000 organisations, including not-for-profit and private for-profit organisations, specialised disability employment agencies, training organisations and social enterprises, all competing in a quasi-market for employment service contracts with government to place people into work as a trigger for revenue payments (Thomas, 2007). A large body of empirical research has documented the challenges of interacting with this system for both job seekers and employers. These include complexity and bureaucracy, poor matching of jobseekers and training with employers' needs, perverse incentives which prevent collaboration, "parking" and "churning" of job seekers to attract payment and disincentives to help job seekers with complex needs (Bowman and Randrianarisoa, 2018; Commonwealth of Australia, 2019).

To understand how the construction industry can interact with such a complex and dysfunctional system, it is useful to refer to Keast's (2015) definition of cross-sector collaboration as a specific form of inter-organisational working where actors from different organisational sectors come together and sacrifice their own interests for a greater collective good through strong interpersonal relationships, supportive processes and mechanisms. A substantial body of research has evolved outside of construction in the area of cross-sector collaboration based on widespread claims about the efficiency, effectiveness, flexibility and innovation benefits it brings in addressing complex social problems like unemployment (Babiak and Thibaullt, 2009, Wilkins et al., 2015). There is general consensus in this literature about the key enablers of genuine and successful cross-sector collaboration in a social policy setting such as social procurement. These enablers include relationship-focussed governance, management and leadership; collaborative systems, processes and cultures; personal relational competencies; micro process such as collaborative language; and the presence of intermediaries to facilitate cross-sector collaboration (Thompson and Perry, 2006; Caldwell et al., 2017; Mandell et al., 2017; de Montignyi et al., 2017; Flynn, 2019; Barraket, 2019).

However, research has also highlighted the risks of managing cross-sector partnerships. For example, Coulson (2005, p. 155) cautions that cross-sector partnerships "are a challenge", and Babiak and Thibaullt (2009) question the assumption that stakeholders in such arrangements collaborate voluntarily, share common goals openly and enjoy equal power. Rather, as Garcia-Canal et al. (2003) note, many so-called partnerships are superficial and plagued by uncooperative and free-riding behaviour and competitive-collaborative tensions which can undermine potential benefits. Babiak andThibaultt's (2009) research highlights a number of key structural, behavioural and strategic challenges which include role clarity, competitive tensions, opportunistic behaviour, mistrust, exploitation, repression, asymmetrical power relations, loss of autonomy in decisionmaking and conflict. According to Babiak and Thibaullt (2009), these problems can lead to wasted time and resources, reduced organisational flexibility and structural atrophy through over-reliance 
on a few partners. Loyalties to existing cross-sector relationships may also restrict partnerships being built elsewhere, generating complacency and reducing innovation and resilience by creating dependencies for resources and competencies on other partners. For these reasons, core organisational support for partnerships can be withdrawn in preference to other priorities, resulting in cross-sector collaborations being starved of resources and undermined by inadequate managerial processes.

Parise and Casher (2003) also note that organisations are often pressured to form partnerships by external imperatives while co-existing in competitive environments outside the arrangement. As Dean (2013), Bromley and Meyer (2017), McNeill (2017) and Caldwell et al. (2017) have pointed out, cross-sector partnerships are not naturally occurring phenomenon since they involve the merging of numerous and often competing organisational missions, goals, values and logics. Therefore, the odds are heavily stacked against success and ambiguity about roles, inter-organisational conflicts, contested leadership and misaligned institutional mandates, and drivers can easily interfere with the smooth running of any social alliance, causing them to be neglected in pursuit of individual interests.

Although there has been no research into cross-sector collaboration in the field of construction, Barraket and Loosemore (2018) revealed numerous barriers that prevent social enterprises working in the construction sector, which might also translate to other third-sector organisations. These include negative perceptions of social enterprise performance; complex, costly and bureaucratic procurement procedures; cosy relationships in existing supply chains; regulatory and performance imperatives which make social enterprises seem high risk; resistance from industry incumbents; disconnects between well-intentioned head office initiatives and site priorities; and ingrained stigmas and biases associated with disadvantaged groups which social enterprises employ. More recently, Troje and Gluch (2019) have also argued that the effective implementation of social procurement in construction will require significant institutional change and the creation of new roles, practices and relationships which do not widely exist.

While these construction-specific insights are useful, they are narrowly focussed, and, as argued above, there is a need for more research into the risks and opportunities of cross-sector collaboration from a much wider range of perspectives. There is also a need to bring them together to address what Troje and Gluch (2019) describe as a lack of conceptualisation of social procurement research in construction. To this end, we adapted Loosemore et al.'s (2020) framework of core enabling factors for cross-sector collaboration as our analytical framework by adding in the risk factors which can act to undermine collaboration reviewed above. This framework is illustrated in Table 1 and provides the basis for the coding of the data collected in relation to our research questions, using the methodology described below.

\section{Method}

Following Yin (2017), and employing an interpretivist epistemology which recognised the socially constructed nature of collaboration and aimed to provide insights into the experiences of crosssector collaboration from the perspectives and lived experiences of our respondents through close interaction with them in the research setting, we adopted a single case study approach. As far as we are aware, the case study described below is the only example internationally of a cross-sector collaborative initiative set up in the construction industry in response to new social procurement requirements. One of the major criticisms of this approach is that the small sample size limits generalisability. On the other hand, as Flyvbjerg (2006) notes, the in-depth nature of single case study research ensures the validity of results is very high, and in circumstances where the case study is unique, it is the only valid approach. Furthermore, in new emerging fields of research such as social procurement which are widely recognised as being in the theory-building phase of development (Barraket et al., 2016; Troje and Gluch, 2019), in-depth case studies are of value in 
providing the basis for the development of theories, propositions and hypotheses which can be empirically tested in subsequent field development.

\section{Case study description}

The case study is a unique collaborative initiative (called a Connectivity Centre) which has been developed by a major international contractor in Australia in response to social procurement requirements on its contracts. It is the uniqueness of this centre that necessitates a single case study approach since currently there is no evidence of any other similar cross-sector initiatives in Australia or indeed in any other part of the world. The Connectivity Centre was physically located adjacent toamajorAU\$1billionhospital project to create a physical space to co-locate the variety of organisations involved in helping local disadvantaged job seekers find sustainable and meaningful work in the project supply chain. Leveraging cross-sector relationships forged over numerous projects where Connectivity Centres had been implemented, this was achieved by facilitating collaboration between the main contractor, client, employers on the project (including construction subcontractors and consultants), training organisations, employment services providers, specialised disability employment organisations, Indigenous support agencies, refugee support agencies, charities and community and support services organisations. These collaborative arrangements were designed to respond to the social procurement targets imposed by the project client which focussed on Indigenous workers, local youth, apprentices, women in construction, local workers, learning workers and long-term unemployed. The range of services delivered in collaboration with these organisations included recruitment, training, mentoring, wrap-around support services and a workplace rotation programme with subcontractors who had back-to-back social clauses inserted into their subcontractors.

\section{Data collection}

In order to collect data about the risks and opportunities of collaboration introduced by new social procurement requirements, five focus groups were conducted with key stakeholders in the case study collaborative (see Table 2). Focus groups were used because they are recognised as an effective way to promote interaction among a diverse group of respondents like those involved in the case study about a specific topic such as collaboration in an open and non-judgemental environment (Morgan, 1988). The focus groups took place in year two of the project, and the sampling criteria for inclusion in the focus group were being a key stakeholder in the Connectivity Centre over this period. Respondents were purposefully sampled to cover the full range of stakeholders involved in the Connectivity Centre, and after gaining ethics clearance, these key stakeholders were identified by the principal contractor who developed and ran the Connectivity Centres. Each respondent was then invited by the independent research team to participate with assurances on anonymity, confidentiality and opportunities to review results and withdraw their data at any time, during or after the focus group process. A key to the effectiveness of the focus group is the presentation of clear instructions about the purpose, process and the questions to be answered, to avoid confusion and maintain discussion. However, too much information can also confuse participants and discourage them from talking (David and Sutton, 2011). So, to ensure the clarity and simplicity of the discussion process, a presentation was given at the start of each focus group to provide a background to the emerging social procurement policy landscape in Australia, the other stakeholders involved in the implementation of these policies, the aims of the research project and the key questions to be discussed. The focus groups were recorded with the permission of the respondents and the questions asked included:

(1) What are your objectives in complying with social procurement requirements on this project and other projects?

(2) What could prevent you from achieving those objectives (risks)? 
(3) What could help you exceed those objectives (opportunities)?

(4) What can be done to maximise the opportunities and mitigate the risks?

(5) What is the nature of your relationships with the other stakeholders involved in the implementation of these policies?

(6) Are there any barriers to collaboration in a social procurement context?

(7) What are the enablers to collaboration in a social procurement context?

Although focus groups have many advantages, as with all research methods there are also some important limitations. For example, it is crucial that every participant has an equal opportunity to represent their views openly without judgement from other group members, and "group-think" must be managed to avoid the views of particular members being suppressed by the development of group norms. These limitations were overcome by the use of experienced facilitation through an independent researcher who had no prior relationship with the respondents and careful forward planning which involved circulation of questions and the presentation in advance (Stewart, 2015).

Each focus group lasted approximately three hours and was conducted the Connectivity Centre on site. Each focus group commenced with a background presentation, and the experienced facilitator provided every respondent the same opportunity to speak, exploring respondent perceptions of risk and opportunity, personal experiences and expectations of working together to meet the project's social procurement targets and how these perceived risks and opportunities affected collaborative potential.

\section{Data analysis}

The focus groups were recorded and transcribed, producing approximately one hundred and twenty thousand words of material for analysis. The data were then analysed using thematic analysis which involved "structuring" the narratives by inductively pinpointing, examining and recording common social structure themes within the data across each response. Following Guest (2012), the inductive thematic analysis involved five stages:

(1) Immersion in the data (repeatedly reading the interview transcripts to obtain a high level of familiarity with the data);

(2) Categorisation/coding (organising and generating an initial list of items/codes from the data set that have a reoccurring pattern as it relates to the research questions and conceptual framework);

(3) Searching for themes (examining how codes combine to form over-reaching themes which are phrases or sentences that identify what the data mean in relation to the research questions and conceptual framework);

(4) Refining themes (continuing to search for data that supported or refuted the emergent themes, allowing further expansion or revision of theme connections between overlapping themes to identify new patterns and issues in the data);

(5) Reviewing, defining and naming themes (through repeated iteration between data collection and analysis until theoretical saturation occurred).

Our research questions were our analytic starting point, and informed by Hsieh and Shannon (2005) and Saldana (2015), we adopted a "directed" approach to coding which was guided by the conceptual framework and analytic categories illustrated in Table 1. Coding involved looking for words and phrases in the data which aligned with the analytical categories in Table 1. In line with Saldana's (2015) recommendations, this occurred both during data collection using analytical memos and after data collection. To demonstrate how themes were identified through the coding 
process, the following quotes from focus groups with subcontractors and employment service providers highlight several perceived barriers to collaboration: costs of compliance, dangerous industry, highly regulated, complexity and not having the knowledge required.

\section{Why are we being asked to step up and take the cost of employing, training and supervising people from disadvantaged backgrounds? (subcontractor)}

\section{Construction is "so dangerous and highly regulated. . . jobs everywhere are becoming more complex. . .and our clients get left further and further behind (employment services provider)}

Following Saldana (2015), these were categorised using the analytical framework in Table 1 and then organised into general themes by reorganising, weaving and condensing the initial analytic codes and categories into narrative form to see how they linked together in relation to our research questions. This process was applied to all the data and tabulated as illustrated in Table 3 using the above example.

Recognising that coding is "primarily an interpretive act" (Salanda, 2015, p. 4), the process described above was undertaken independently by a team of researchers from both within and outside the construction industry to provide different perspectives on the data (Hayfield and Huxley, 2015). Discussions of conflicting themes occurred until $100 \%$ inter-rater was achieved, providing a high level of confidence in the validity of the emergent themes which are presented below in relation to each research question. In line with the traditions of thematic research, these themes are presented below in narrative form supported by selected quotes in relation to each research question. Given the large amount of data collected from so many stakeholders, it is not possible to recount everything the respondents said, so the results use selected representative quotes from each stakeholder group to illustrate the main themes which emerged from the data.

\section{Results}

Research question one: What perceived risks and opportunities does social procurement create for key stakeholders involved in implementing social procurement in construction?

The number of themes relating to risk was over three times the number of themes relating to opportunity, indicating that social procurement is seen as more of a risk than an opportunity by the focus group key stakeholders. These themes are discussed in more detail below in relation to each stakeholder group.

\section{Risk themes}

Subcontractors were by far the most vocal about the risks of social procurement. Subcontractors highlighted the extra costs of supervising workers and trainees who were perceived to present potential threats to productivity and safety in a highly performance driven and regulated industry.

Why are we being asked to step up and take the cost of employing, training and supervising people from disadvantaged backgrounds? (subcontractor)

These risks were described by subcontractors as "cumulative", since social procurement policy imposed a new set of employment requirements on each project. This was seen as a "unique burden" on the construction industry, exacerbated by the small size of most subcontracting businesses. Subcontractors also expressed resentment towards policymakers who were perceived to be "off-loading" risks of welfare, with no understanding or concern for the industry's capacity to deliver. Principal contractors were seen to be passing these risks in back-to-back contracts down the supply chain. Workers and trainees preferred through social procurement (such as Indigenous people and refugees) were also described as "displacing" traditional sources of labour, who were 
perceived as more worthy of jobs because they had gained the necessary experience and qualifications to work in the industry.

For government stakeholders, the risks of social procurement were perceived to be minimal since they had been successfully transferred to the construction sector at minimal cost and effort. There was little interest by government stakeholders in how the industry met its targets, although some concerns were raised about the sustainability of jobs indicating internal contradictions in the intent of the policies and a desire to transfer risk to the private sector.

As long as it's the same for everyone to tender then we do not care what companies do to deliver on the social outcomes (government)

For employment services system providers, despite excitement about the many new employment opportunities offered by social procurement, there was a reluctance to direct vulnerable candidates into a highly regulated, risky and sceptical industry (reported to be suffering from "social procurement fatigue") and a reported hesitance on the candidates' parts to apply for jobs available.

Construction is "so dangerous and highly regulated. . . jobs everywhere are becoming more complex. . .and our clients get left further and further behind (employment services provider)

The major identified risk for education stakeholders was in building consistent relationships with a transient, project-based and highly regulated industry. The employment network was also criticised for trapping people in a cycle of inappropriate training to meet their compliance obligations reducing employability and increasing their risk of dropping-out of employment.

Social procurement should not be just about projects. . it should be about building communities. .. and building careers (education)

For social enterprises, the main risks of social procurement revolved around the potential vulnerabilities of over-dependence on what was described as a sceptical industry, being forced to engage with polices that could easily change.

You find you are having to educate them (construction companies) on the regulations as much as sell your own services to them (social enterprise).

\section{Opportunity themes}

Government agencies and social enterprises were by far the most optimistic about social procurement. Subcontractors indicated an untapped willingness to help disadvantaged people in the supply chain, but respondents had difficulty in articulating the benefits of social procurement other than the possibility of forcing competitors, who did not have the resources to comply, out of the market for public sector projects.

\section{Our competitors will drop out because of this policy (subcontractor)}

In complete contrast, government stakeholders saw social procurement as a significant new opportunity. Various reasons were articulated which included the "visibility" of construction work in the community; the sector's large size and preponderance of low-skilled well-paid jobs; major infrastructure pipelines; government's ability to control the whole procurement process from planning through design, construction and operations; and the ease by which welfare risks could be transferred to the private sector at minimal effort and cost.

There is something visual and tangible about construction that part of the community... if you are building a road or a bridge in the community and local kids are working on it (government) 
Reflecting the privatised nature of the employment services market in Australia, employment sector stakeholders described social procurement as a major revenue-generating opportunity to their businesses, but also an opportunity for candidates to gain training and employment through stronger connections with a major industry. The Connectivity Centre was seen as key to harnessing these opportunities because of the employment sector's weak historical ties with the construction sector.

The Connectivity Centre is essential. . . to provide the coordination across the supply chain between the many subcontractors and the many Job Actives operating in a project location (employment)

For educational stakeholders, social procurement was seen as a major opportunity for candidates to develop new career paths, although the project-based nature of the construction industry raised concerns that these would only be short-term.

It's an opportunity done properly to develop long term careers for disadvantaged people who are going to be a burden on the welfare and corrective services system (education)

Finally, social enterprises saw social procurement as a potentially major, but largely unrealised, opportunity which required closer interaction with the construction sector.

We have been getting companies now coming to us before they tender for these projects, asking us to help them how they can meet their targets. . . this is a big new opportunity" (social enterprise)

Research question two: How do these perceived risks and opportunities affect collaborative potential in these new organisational arrangements? Four broad cross-cutting themes were evident around how these perceived risks and opportunities affected collaborative potential. In rank order, these included policy design and implementation, nature of construction industry, supply of suitable candidates and need for education. They are discussed in detail below.

\section{Policy design and implementation}

The strongest common theme was concern about the design and implementation of social procurement policies. Policy challenges included inflexibility, instability, overlaps, conflicts and temporal misalignments. Subcontractors complained about the inflexibility of social procurement policy targets but felt fatalistic about being unable to change them. They were mistrusting of social procurement policy intent, arguing that the government had developed the easiest version for them but the most onerous for the industry. They also had little understanding of why the policy was being introduced, and perceived targets to be imposed top-down and impossible to meet, making gaming and exploitation of the system inevitable. Focus group narratives indicated a deep sense of cynicism, a compliance mentality and a minimalistic tick-box approach.

We are trying to implement something that's been designed for other industries where it's easier to employ these people (subcontractor)

Government stakeholders raised questions regarding the lack of evidence around the effectiveness of such policies and knowledge of how to collect that evidence reliably.

The sustainability of outcomes is not measured very well (Government)

Employment services stakeholders highlighted poor communication between inter-related policy areas and a perceived dissonance between government expectations for instantaneous success, the complexity of the problems faced and the capacity of the construction sector to deliver. Concerns were also expressed about the competitive nature of the employment sector and the need to collaborate through initiatives like the Connectivity Centre. 
Providing job opportunities is complex. .. the issues cut across many areas which all have to be coordinated but which do not talk to each other (employment services provider)

Education stakeholders complained about conflicting Australian state and federal government policies, which they felt made it difficult to collaborate and prepare candidates for working in the industry. Like employment stakeholders, the Connectivity Centre was seen as critical in facilitating the cross-sector collaborations required to address candidates' complex needs.

We need a helicopter overview to see these contradictory policies (education)

Social enterprises expressed concern about investing on the back of social procurement policies, which they considered unstable.

So there is a danger than if we take one on and expand and then they pull the carpet out from underneath us (social enterprise).

\section{Nature of construction industry}

The second strongest theme in the focus group narratives related to the construction industry's defining norms and culture, structure, networks, recruitment practices and path dependencies, regulatory environment and relationships with the community. For subcontractors, social procurement policies displaced existing informal networks and processes through which people are normally recruited. High-risk licenced trades such a plumbing and electricians were seen to pose particularly strong educational barriers to entry.

There is a big knowledge gap between how we traditionally employ and how we are expected to employ now (subcontractor)

For employment services agencies, the subcontracted and transitionary nature of construction project organisations presented significant transaction costs and barriers to collaboration in working with the industry.

The subcontracting model of the industry makes social procurement much more difficult because the numbers of interfaces increase hugely across which Job Actives have to work (employment)

For government, the industry was seen as an easy environment to mandate employment requirements due to its significant purchasing power and the perceived ease of simply inserting clauses into contracts to mandate these requirements. Some reservations were raised about the ability of the industry to respond, but this was seen as an industry rather than government problem.

All we have to do is insert clauses in their (contractors') contracts. (government)

For the education providers, social procurement policies only provided a "sugar hit". Projects were described as temporary opportunities to prepare people for work, and educator narratives reflected scepticism about the commitment of construction companies to providing sustainable jobs and of subcontractors' capacity to manage the risks involved.

These companies have no intention to create permanent jobs and because they are on projects it's hard for them to do it. . these projects only last for a while (education)

For social enterprises, the industry was seen as a "closed-shop" with strong perceptions of the ideal construction worker, long-standing industry incumbents, problematic union relationships, negative perceptions of social enterprises, strong and long-established existing relationships between existing players and risky procurement and payment practices. 
There is a lot of potential stigma around any not for profits [in the construction industry] and social enterprises tend to fit into this group (social enterprise).

\section{Supply of suitable candidates and quality of jobs}

The third strongest common theme in the focus group narratives related to the supply of suitable candidates targeted by social procurement policies. Subcontractors in particular, complained about not being able to meet the targets being set by principal contractors, despite their best efforts. This was being exacerbated by the overlapping requirements across multiple projects. For subcontractors, the Connectivity Centre was a critically important resource to provide access, advice and support for managing suitable candidates. "Suitable" was articulated to mean candidates with the necessary knowledge, skills and attributes to work in the industry, and there was strong agreement that the supply of the "easiest" suitable candidates (those that required minimal investment of time and resources to upskill) was already running out and that this would only get worse.

When all the other government projects come on stream then there is going to be a massive supply problem very quickly. . . we are already seeing it now (subcontractors)

Government stakeholders noted the difference between "forced jobs" and "real jobs", implying that the mandated nature of social procurement policies was unsustainable unless there was a change in the culture of the construction supply chain to engage voluntarily. The Connectivity Centre was again seen as central to enabling this to happen.

Are we just trying to force people into work because we are focusing on the jobs (government)

Employment services stakeholders found it difficult to recruit and prepare candidates due to difficulties in communicating with subcontractors around project workforce needs. Background checks and drug testing were seen as major barriers to employment of many candidates, who see the industry as inaccessible, highly regulated and specialised.

We had 180 jobs available. . we personally invited 85 and only 24 turned up and then 15 got offered jobs. .. they see all the checks... and they do not come (employment)

Education stakeholders argued that the policies were oriented towards the employment of easier cohort groups. They saw construction as a stepping stone on a pathway back into work and noted the importance of developing generic skills for working in other industries when projects finish.

I notice that in the targets companies are steering towards the easier groups (education) Social enterprise concerns revolved around candidates not being matched to construction skills shortages and union resistance.

Not being able to set foot on a worksite because we do not have an enterprise agreement with them (the union) (social enterprise).

\section{Need for education}

The least strong common theme related to the importance of education. For subcontractors, the value of education was in understanding what the term social procurement meant, why these policies were being introduced and what was needed to comply. For subcontractors, the Connectivity Centre was repeatedly referred to as an important educational resource.

The Connectivity Centre educated us as to what we are trying to do here. . (subcontractors) 
For government, the value of educating was about developing internal and external capabilities to manage these new relationships and networks.

\section{A big part of the process has to be education of the subcontractors (government)}

For the employment services sector, education was needed to building understanding and stronger connections with a new industry and with others involved in the implementation of these policies.

\section{Education to understand how the industry works and its expectations (employment)}

Education stakeholders pointed to the lack of educational support for preparing candidates to work in the industry, especially basic work-readiness skills such as attendance, punctuality, eating properly and working with others in teams. Generic skills that enable employment in other industries after a construction project has finished were also deemed to be important.

The project managers are just not up to speed on this. . their priority is to get their job built. . . this is just another requirement (education)

For social enterprises, better education was needed from government to better promote the benefits of social procurement to the construction industry and the social enterprise sector. Both sectors were seen as largely ignorant of these new policies.

\section{Government should be promoting social procurement by advertising the benefits of it, not mandating it (social enterprise).}

\section{Discussion}

In responding to the need for more multi-stakeholder research into cross-sector collaboration in a construction social procurement context, the results above provide numerous new insights into the risks and opportunities of cross-sector collaboration in the implementation of emerging social procurement policies.

\section{The risks and opportunities of cross-sector working in construction}

First, in addressing research question one, our results strongly support the findings of Keast and Mandell (2013) and McNeill (2017) by demonstrating that cross-sector partnerships are challenging and involve significant risks for those involved. Although the risks presented by social procurement varied from stakeholder-to-stakeholder, they were perceived to be the greatest for subcontractors who made repeated reference to increased costs, lower productivity and reduced safety. This supports recent research by Loosemore et al. (2019) whose survey of 70 Australian subcontractors also revealed significant perceived business risks associated with safety, productivity and costs with disengaged youth being perceived as the highest risk cohort, followed by migrants and refugees, people suffering disability, ex-offenders, women and Indigenous workers. However, expanding this research across other stakeholder groups, it was also found that employment priorities reflected these perceptions and that perceived barriers to employment varied significantly across these groups, with smaller and younger firms perceiving the greatest barriers - particularly for women and Indigenous workers. On the other hand, government and social enterprise stakeholders were by far the most optimistic about these policies which they saw as building political capital in communities, tapping into the resources and expertise of the private sector and forging new untapped links with a major employment industry to help them address social challenges like unemployment in the communities which they serve. Compared to risks, the opportunities associated with social procurement have received far less attention, and this provides a new positive insight into the benefits of social procurement, although these benefits are not always articulated from the perspectives of the disadvantaged people that the policies are ultimately meant to help. The political dimensions of social procurement are particularly interesting and justify further research. 
The findings indicate that the risks of social procurement are seen as particularly problematic due to the dynamic and project-based nature of the industry. Furthermore, these policies are perceived as being imposed top-down without any choice by regulatory imperatives and government "outsiders" who are seen to be shifting risk, without any support or for any consideration of the construction sector's capacity to respond.

\section{Developing new relational skills, knowledge and competencies to facilitate cross-sector working}

Social procurement was new for all stakeholder groups, and most respondents had not heard the term before, despite having to comply with these policies over numerous projects and over a number of years. This highlights a lack of education in this area supporting implementation, and in support of Troje and Gluch (2019), our results show that the skills, knowledge and organisational structures needed to effectively manage the risks (and opportunities) it creates have not yet evolved. Adding to Troje and Gluch (2019), the results indicate these are unlikely to evolve through traditional functions like project management, human resources, corporate social responsibility or sustainability. In line with Barraket (2019), the results indicate that the development of specialised intermediaries like The Connectivity Centre can facilitate the cross-sector collaborations needed for these policies to work. However, the relational capital, skills, competencies and knowledge needed to establish and run these intermediaries are very different to those which typically exist in the field of construction project management education and training. For example, the Project Management Body of Knowledge (PMBOK, 2017) makes no references to social procurement and cross-sector working. Therefore, the results point to the need for a new body of knowledge and set of competencies to be developed to enable the construction sector to meet its new social procurement obligations.

\section{The role of intermediaries in facilitating cross-sector collaboration}

The findings support Barraket (2019) who shows that more research into intermediaries as boundary spanners and facilitators of cross-sector collaboration is needed to enable better incorporation into social procurement policy implementation. Finally, the results have provided new empirical evidence to support Agogue et al.'s (2017) and Barraket's (2019) contention that the challenges of intermediaries operating in unstable, dynamic and transitionary fields such as the construction sector are very different to those operating in more stable and simple environments, because they have to respond continually to the changing needs of the communities and projects in which they are based. Regional intermediaries to coordinate social procurement requirements across different projects in a geographical area (perhaps at a local authority, city or state level) are a potential way to reduce these challenges and to scale-up the social impact of social procurement through industries like construction. Increasing the scale of social impact could also then potentially attract social impact investing, and our findings indicate that regional Connectivity Centres should be explored in future social procurement policy circles.

\section{The importance of effective risk management}

As well as providing new insights to the types of risks that social procurement creates in industries like construction for the various stakeholders involved in implementing these policies, the results contribute new insights into the way that these risks are being managed. In particular, the results indicate that the normal practice of transferring risks down the construction supply chain to the point of least resistance is also being applied in a social procurement context. This is at odds with the widely accepted principles of effective risks management, which state that risk should only be given to parties who have the necessary resources, information and willingness to manage them and which can charge an appropriate premium to do so (Abrahamson, 1983). Findings also indicate that effective risk management of these policies at all levels of implementation is critical for effective policy implementation, and, when done badly, create behaviours and attitudes which are 
diametrically opposed to those which underpin effective cross-sector collaboration (Keast, 2015). The results highlight the critical role of the Connectivity Centre as a unique project-based intermediary in managing these risks and opportunities for all stakeholders.

The findings also indicate that in addition to the normal challenges posed by cross-sector partnerships, poorly managed risks significantly heighten relational tensions produced by social procurement. In support of Parise and Casher (2003), the results indicate that this effect is exacerbated when pressures to form cross-sector partnerships are perceived to be imposed by external parties without any regard for those handed the risk. In support of Babiak and Thibaullt (2009), the research shows that such perceptions are likely to manifest in many negative behaviours such as opportunism, exploitation, gaming and compliance responses. The results also reflect the types of market distortions raised by Barraket and Weissman (2009), as smaller construction businesses are potentially forced out of the markets where these policies are being introduced. These anti-collaborative and anti-competitive behaviours are unlikely to optimise the outcomes of such policies and only transfer the risks back to the policy-makers who created them in the first place.

\section{Information asymmetries and perverse incentives}

In addressing how collaborative potential was affected in these organisational arrangements, this research exposes information asymmetries and perverse incentives which can act to undermine effective collaborative relationships. Information asymmetries uncovered in this research largely revolved around the rationale, wider context and intent of social procurement policies, what were needed to comply with them, as well as the relative business models, functions and contributions of various actors required to collaborate in meeting the targets being set. Perverse incentives highlighted within the data included the competitive tensions and imperatives within the employment sector, risk-transfer policy culture and the unrealistic targets and timeframes in which these targets need to be met.

The concept of information asymmetries has its origins in principal-agent theory and the formative work of Akerlof's (1970) "Market for Lemons" and refers to transactions where one party has more or better information. The theory predicts that information asymmetries result in a three main choices for contractors (principals): not to enter into the transaction (not tendering on a project with social procurement targets), engaging in "adverse behaviour" (such as choosing the easiest candidates to employ, giving them low quality work or doing the minimum to comply) or behaving in a "morally hazardous" manner (such as gaming the system to make it appear as if they are complying). It is notable that each of these behaviours was mentioned by our respondents as potential and actual responses to these policies. However, given the need to generate work in a lowmargin industry like construction, it is more likely that adverse and morally hazardous behaviour will occur in response to the imposition of these new social procurement requirements. This highlights the crucial need for government policy-makers to monitor and measure the implementation of these policies carefully. Worryingly, our findings raise concerns that this is not happening at the moment.

\section{Conclusion}

In contributing to the emerging construction social procurement debate and in addressing the lack of research into the risks and opportunities of social procurement in construction, this research has highlighted the multiple challenges of implementing collaborative social procurement policies in highly regulated, transient and project-based industries like construction which have little experience or inclination to form the types of multiple cross-sector partnerships which are central to the effective implementation of these policies. The findings contribute new theoretical and practical insights to social procurement research in construction by highlighting the potential value of 
intermediaries like the Connectivity Centre in mitigating the risks and maximising the opportunities of cross-sector collaboration which lies at the heart of effective social procurement policy implementation. The results show that social procurement can create many new "shared value" opportunities for the stakeholders involved in the process, including opportunities to showcase their citizenship credentials and gain competitive advantage, leveraging construction spending to create social value in the communities in which they operate and creating new value-adding connections into previously disconnected sectors. However, these perceptions of value are quite narrow compared to those articulated in the social procurement literature, and the findings also illustrate that new "relational" skills, knowledge and competencies are required to manage these new crosssector relationships which do not currently exist in construction project management frameworks. The findings expose many challenges of working across sectors in highly transitionary project-based environments like construction and indicate that the potentially enormous opportunities which social procurement offers to communities are being undermined by stakeholder nervousness about policy design, stability and implementation, poor risk management, information asymmetries, perverse incentives, candidate supply constraints, scepticism, traditional recruitment practices and industry capacity constraints. While these risks can be mitigated through collaborative initiatives like Connectivity Centres, desired social outcomes cannot be achieved without careful monitoring and enforcement of these policies.

The opportunities which these policies present to all stakeholders are potentially significant but undermined by a mistrusting, unsustainable, fragile and compliance-based environment which, if left unresolved, is unlikely to lead to long-term sustainable outcomes for people suffering disadvantage in the communities in which the construction sector builds. The findings indicate that when social procurement policy requirements are excessive and imposed top-down, with little understanding of the construction industry's capacity to comply, intended social outcomes are unlikely to be achieved.

While the limitations of the case study approach adopted are recognised, this research raises important new insights for researchers, policy-makers and those involved in implementing these policies to contemplate. In particular, the new cross-sector insights offered by this research into the risks and opportunities of social procurement highlight the potentially damaging impact on crosssector collaboration of misaligned and unfair perceptions of risk and opportunity distributions among stakeholders. Adding to the theoretical development of the field of social procurement and cross-sector collaboration, the results also highlight the need to further investigate and resolve apparent information asymmetries and perverse incentives, policy inflexibility, instability, overlaps, conflicts and temporal misalignments which undermined the ability to collaborate to effectively implement these policies in practice.

From a theoretical perspective, the research highlights the potential value of risk management, principal-agent and intermediary theories in further understanding the important issues that have been raised in this research. From a practical perspective, the findings suggest that policy-makers should ensure that policy conflicts and perverse incentives that undermine collaboration are resolved, that the risks and opportunities of social procurement are clear and shared, that their policies reflect and acknowledge the sector's constraints and challenges and that the parties responsible for implementation have the incentives, knowledge, resources and time to collaborate to do so.

At a project level, managers should ensure that there are effective systems, support, cultures, incentives and structures in place to facilitate and encourage collaboration by eliminating information asymmetries through education and demonstrating the shared value of collaboration through building trusting relationships and open communication and managing the risks for all involved. At an organisational level, organisations must be prepared to invest time and resources in building collaborations and relationships and be able to think more broadly than simply the benefit 
of their own organisation. At an individual stakeholder level, managers must ensure that people have the appropriate skills, competencies, attitudes and capabilities to work across different sectors in a collaborative environment.

In drawing all of these levels together, this research addresses the significant potential of innovative intermediaries like the Connectivity Centre to face the challenges that have been highlighted. Nevertheless, despite a growing body of literature on intermediaries, there is much more research needed on how intermediaries can work in temporary, transitionary project-based industries like construction.

\section{References}

Armstrong-Stassen, M., \& Schlosser, F. (2010). When hospitals provide HR practices tailored to older nurses, will older nurses stay? It may depend on their supervisor. Human Resource Management Journal, 20(4), 375-390, https://doi.org/10.1111/j.1748-8583.2010.00143.x

Abrahamson, M.W. (1983), "Risk management", International Construction Law Review, Vol. 241, p. 244.

Agogue, M.E., Berthet, T., Fredberg, P., Le Masson, B., Segrestin, M., Stoetzel, M., Wiener, M. and Ystrom, A. (2017), "Explicating the role of innovation intermediaries in the 'unknown': a contingency approach", Journal of Strategy and Management, Vol. 10 No. 1, pp. 19-39.

Akerlof, G.A. (1970), "The market for 'lemons': quality uncertainty and the market mechanism", Quarterly Journal of Economics, The MIT Press, Vol. 84 No. 3, pp. 488-500.

Babiak, K. and Thibaullt, L.A. (2009), "Challenges in multiple cross-sector partnerships nonprofit and voluntary sector quarterly", Nonprofit and Voluntary Sector Quarterly, Vol. 38 No. 1, pp. 117-143.

Barraket, J. (2019), "The role of intermediaries in social innovation: the case of social procurement in Australia", Journal of Social Entrepreneurship, Vol. 11 No. 2, pp. 194-214, doi: 10.1080/19420676.2019.1624272.

Barraket, J. and Loosemore, M. (2018), "Co-creating social value through cross-sector collaboration between social enterprises and the construction industry", Construction Management and Economics, Vol. 36 No. 7, pp. 394-408.

Barraket, J., Keast, R. and Furneaux, C. (2016), Social Procurement and New Public Governance, Routledge, New York, NY.

Barraket, J. and Weissman, J. (2009), Social Procurement and its Implications for Social Enterprise: A literature review. The Australian Centre for Philanthropy and Nonprofit Studies, Queensland University of Technology, Brisbane.

Bowman, D. and Randrianarisoa, A. (2018), Missing the Mark: Employer Perspectives on Employment Services and Mature Age Jobseekers in Australia, Brotherhood of St Laurence, Fitzroy, Vic.

Bromley, P. and Meyer, J.W. (2017), "They are all organisations: the cultural roots of blurring between non-profit", Business and Government Sectors, Administration and Society, Vol. 49 No. 7, pp. 939-966.

Caldwell, N.D., Roebrich, J.K. and George, G. (2017), "Social value creation and relational coordination in public-private collaborations", Journal of Management Studies, Vol. 54 No. 6, pp. 906-928.

Canadian Procurement Strategy for Aboriginal Business (2016), Canadian Procurement Strategy for Aboriginal Business, Government of Canada, Ottawa, Canada.

Commonwealth of Australia (2019), The Senate Education and Employment References Committee Jobactive: Failing Those it Is Intended to Serve (C) Commonwealth of Australia 2019, Commonwealth of Australia, Canberra. 
Coulson, A. (2005), "A plague on all your partnerships: theory and practice in regeneration", The International Journal of Public Sector Management, Vol. 18 No. 2, pp. 151-163.

Cutcher, L., Orminston, J. and Gardner, C. (2019), “'Double-taxing' indigenous business: exploring the effects of political discourse ion the transfer of public procurement policy", Public Management Review, Vol. 22 No. 9, pp. 1398-1422.

David, M. and Sutton, C.D. (2011), Social Research: An Introduction, Sage, London.

de Montigny, J.G., Desjardins, S. and Bouchard, L. (2017), "The fundamentals of cross-sector

collaboration for social change to promote population health", Global Health Promotion, Vol. 26 No. 2, pp. 41-50, 1757-9759.

Dean, A. (2013), Tackling Long-Term Unemployment Amongst Vulnerable Groups, Organisation for Economic Cooperation and Development (OECD), Paris.

Doherty, B., Haugh, H. and Lyon, F. (2014), "Social enterprises as hybrid organizations: a review and research agenda", International Journal of Management Reviews, Vol. 16 No. 4, pp. 417-436.

Esteves, A.M. and Barclay, M. (2011), "Enhancing the benefits of local content: integrating social and economic impact assessment into procurement strategies", Impact Assessment and Project Appraisal, Vol. 29 No. 3, pp. 205-215.

European Union (2014), "Directive 2014/24/EU of the European parliament and of the council, of $26^{\text {th }}$ February on public procurement and repealing directive 2004/18/EC", Official Journal of the Eurpoean Union, L94/65, available at: http://eur-lex.europa.eu/legalcontent/EN/TXT/?uri5CELEX:32014L0024 (accessed June 2014).

Flynn, A. (2019), "Investigating the implementation of SME-friendly policy in public procurement", Policy Studies, Vol. 39 No. 4, pp. 422-443.

Flyvbjerg, B. (2006), "Five misunderstandings about case study research case study", Qualitative Inquiry, Vol. 12 No. 1, pp. 219-245.

Garcla-Canal, E., Valdez-Llaneza, A. and Ari nio, A. (2003), "Effectiveness of dyadic and multi-party joint ventures", Organization Studies, Vol. 24 No. 5, pp. 743-770.

Greenhalgh, B. and Squires, G. (2011), Introduction to Building Procurement, Routledge, London.

Guest, G. (2012), Applied Thematic Analysis, Sage, Thousand Oaks, California, p. 11.

Hayfield, N. and Huxley, C. (2015), "Insider and outsider perspectives: reflections on researcher identities in research with lesbian and bisexual women", Qualitative Research in Psychology, Vol. 12 No. 2, pp. 91-106.

Hsieh, H. and Shannon, S.E. (2005), "Three approaches to qualitative content analysis", Qualitative Health Research, Vol. 15 No. 9, pp. 1277-1288.

Indigenous Procurement Policy (2015), Indigenous Procurement Policy, Australian Government, Canberra.

ISO 20400 (2017), "Sustainable procurement - guidance", International Organization for Standardization, Geneva, Switzerland.

Keast, R. (2015), A Guide to Collaborative Practice: Informing Performance Assessment and Enhancement, Queensland Family and Children's Commission, Brisbane, Queensland.

Keast, R. and Mandell, M.P. (2013), "Network performance: complex interplay of form and action", International Review of Public Administration, Vol. 18 No. 2, pp. 27-45.

Loosemore, M. (2016), "Social procurement in UK construction projects", International Journal of Project Management, Vol. 34 No. 2, pp. 133-144.

Loosemore, M., Alkilani, S. and Mathenge, R. (2019), "The risks of and barriers to social procurement in construction: a supply chain perspective", Construction Management and Economics, Vol. 38 No. 6, pp. 552-569, doi: 10.1080/01446193.2019.1687923.

Loosemore, M., Bridgeman, J. and Keast, R. (2020), "Reintegrating ex-offenders into work through construction: a case study of cross-sector collaboration in social procurement", Building Research and Information, Vol. 48 No. 7, pp. 731-746, doi:

10.1080/09613218.2019.1699772. 
Mandell, M.P., Keast, R. and Chamberlain, D. (2017), "Collaborative networks and the need for a new management language", Public Management Review, Vol. 19 No. 3, pp. 326-341.

McCrudden, C. (2004), "Using public procurement to achive social outcomes", Natural Resources Forum, Vol. 28 No. 4, pp. 257-267.

McNeill, J. (2017), "Enabling social innovation assemblages: strengthening public sector involvement", A Thesis Submitted for the Degree of Doctor of Philosophy, Institute for Culture and Society, Western Sydney University, Sydney, May 2017.

Morgan, D.L. (1988), Focus Groups as Qualitative Research, Sage, London.

Murray, M. and Dainty, A. (2013), Corporate Social Responsibility in the Construction Industry, Routledge, London.

Parise, S. and Casher, A. (2003), "Alliance portfolios: designing and managing your network of business-partner relationships", Academy of Management Executive, Vol. 17 No. 4, pp. 2539.

PMBOK (2017), A Guide to the Project Management Body of Knowledge (PMBOK ${ }^{\circledR}$ Guide), 6th ed., Foundational Standards, New York, NY.

Public Services (Social value) (2012), Public Services (Social value) Act 2012 (UK), UK Cabinet Office, London.

Raiden, A., Loosemore, M., King, A. and Gorse, C. (2018), Social Value in Construction, Routledge, London.

Saldana, J. (2015), The Coding Manual for Qualitative Researchers, Sage, New York, NY.

Stewart, D.W. (2015), Focus Groups: Theory and Practice, Sage, Thousand Oaks, California.

Tanekenov, A., Fitzpatrick, S. and Johnsen, S. (2018), "Empowerment, capabilities and homlessnes: the limitations of employment-focused social enterprises in addressing complex needs", Housing, Theory and Society, Vol. 35 No. 1, pp. 137-155.

The Public Law 95-507 Act (1978), Public Law 95-507 Act - OCT. 24 (1978), United States of America Government.

Thomas, M. (2007), "A review of developments in the Job Network", Research Paper no. 15 200708, Social Policy Section, Canberra (accessed 24 December 2007).

Thompson, A.M. and Perry, J. (2006), "Collaboration processes: inside the black box", Public Administration Review, Vol. 66 Supplement, pp. 20-31.

Troje, D. and Gluch, P. (2019), "Populating the social, realm: new roles arising from social procurement", Construction Management and Economics, Vol. 38 No. 1, pp. 55-70, doi: 10.1080/01446193.2019.1597273.

Wilkins, P., Phillimore, J. and Gilcrest (2015), Working Together: Evidence of Collaboration from the Reports of Independent Watchdogs, Australian and New Zealand School of Government, Carlton, Melbourne, Victoria.

Yin, R.K. (2017), Case Study Research and Applications: Design and Methods, Sage Publications, London.

Note: This project was funded by an Australian Research Council grant: LP170100670. 